\title{
LÍNGUA E CULTURA POP JAPONESA NO BRASIL - RESULTADOS DE UMA PESQUISA DE CAMPO EM SÃO LUÍS (MA) E FORTALEZA (CE)
}

\author{
Elisa Massae Sasaki ${ }^{1}$
}

Resumo: Este artigo apresentará algumas considerações feitas a partir da pesquisa de campo sobre a língua e cultura japonesa no Brasil, realizada nas cidades de São Luís (MA) e Fortaleza (CE). Isso foi parte de uma pesquisa chamada "Japanese language as the networking ties" que tinha como objetivo elucidar o papel da língua japonesa enquanto "laço", isto é, conhecer em que medida a língua japonesa contribui para formar comunidades fora do Japão. A pesquisa focou nas pessoas do grupo chamado 'nihongo-jin' que, em entrevistas, relataram o contato que tiveram com a cultura pop japonesa e como isso levou-os a estudarem a língua japonesa.

Palavras-chave: Língua Japonesa; Cultura Japonesa; Cultura Pop Japonesa; Pesquisa de Campo; Brasil.

Abstract: This article will present fieldwork on Japanese language and culture in Brazil, achieved in São Luís (MA) and Fortaleza (CE). It was part of a research study called "Japanese language as the networking ties" which aimed to elucidate the role of Japanese language as "ties", emphasizing how the Japanese language can contribute to forming communities outside of Japan. The research focused on the people of the group called "nihongo-jin" who reported, in the interview, their contact with Japanese pop culture and how it led them to study Japanese language.

Keywords: Japanese language; Japanese culture; Japanese pop culture; fieldwork; Brazil.

\section{Introdução}

Entre 2011 e 2012, realizou-se uma pesquisa chamada "Japanese language as the networking ties”〈紐帯としての日本語〉 promovida pela Universidade de Estudos

1. Professora Adjunta do Setor de Japonês, do Departamento de Letras Clássicas e Orientais (LECO), do Instituto de Letras (ILE), da Universidade do Estado do Rio de Janeiro (UERJ). E-mail: elisamassae@gmail.com 
Estrangeiros de Tóquio ${ }^{2}$, em vários países como a China, Coreia, Indonésia, Taiwan e Brasil. Neste último país, a primeira fase da pesquisa foi realizada em julho e agosto de 2011, no Rio de Janeiro (RJ) ${ }^{3}$, entrevistando representantes das entidades nipo-brasileiras assim como professores de língua japonesa da cidade (TAKEDA, KITAHARA, 2014, p.6-14). E em agosto de 2012 foi realizada uma segunda etapa da pesquisa de campo nas cidades de São Luís (MA) e em Fortaleza (CE).

Para buscar entender o papel da língua japonesa enquanto "laço", isto é, como a língua japonesa pode contribuir para formar comunidades fora do Japão, essa pesquisa partiu do pressuposto de que há três grandes grupos em que o idioma japonês promove uma união: (a) dos japoneses residentes no exterior (nihonjin 日本人), (b) dos descendentes de japoneses (nikkeijin 日系人) e (c) dos não-japoneses ou aqueles que não têm nenhuma origem japonesa, mas que dominam a língua japonesa e/ou que vivem ou trabalham com assuntos relacionados ao Japão (nihongo-jin 日本語人) (NOMOTO, 2014).

Muitas vezes, os estudiosos apontam que, num primeiro momento, a língua e a cultura japonesa no Brasil foram fortemente associadas ao estabelecimento dos japoneses nesse país através da sua imigração ao longo do século $\mathrm{XX}^{4}$, o que justifica a extensão dos dois primeiros grupos - (a) de japoneses residentes no exterior (nihonjin) e (b) descendentes de japoneses (nikkeijin) - pois a língua era uma forma importante de manutenção de suas raízes e identidade nipônica, além dos hábitos e costumes culturais e sociais (MORIWAKI, NAKATA, 2008; MORALES, 2008; MUKAI et al., 2012). À medida que os japoneses foram se fixando cada vez mais no Brasil, surgindo gerações posteriores, eles foram adotando cada vez mais a língua do país hospedeiro - a portuguesa - como um aspecto importante de integração à sociedade brasileira, assim como de inserção no mercado de trabalho e ascensão social e profissional. No final do século XX, a língua japonesa no Brasil passou a ser considerada mais uma língua estrangeira do que língua materna pela comunidade nikkei. Concomitantemente, à medida que as primeiras gerações (isseis) foram envelhecendo, os seus filhos e netos foram se distanciando cada vez mais da língua japonesa falada pelos seus avós e pais. Se antes a língua japonesa era falada dentro da casa dos migrantes japoneses, as gerações seguintes, embora entendessem o que os mais velhos falavam em japonês, se expressavam em português.

Além disso, nesse mesmo final do século XX, verificamos a migração de brasileiros descendentes de japoneses ao Japão (SASAKI, 2009). Isso se iniciou no final dos anos 1980 e depois de mais de duas décadas, a permanência de brasileiros foi aumentando cada vez mais e passamos a verificar um surgimento da primeira geração

2. Essa pesquisa contou com financiamento do Japan Society for the Promotion of Science (JSPS), um órgão do Ministério da Educação, Cultura, Esporte, Ciência e Tecnologia do Japão (MEXT).

3. No Brasil, esta pesquisa foi conduzida em conjunto com a Universidade do Estado do Rio de Janeiro (Uerj).

4. Sobre a imigração japonesa no Brasil, veja: SAITO (1980); SAKURAI (2000); SAKURAI \& COELHO (2008); CARNEIRO \& TAKEUCHI (2010) e MOTOYAMA (2011). 
de filhos de brasileiros nascidos no Japão - que podemos chamar de nisseis brasileiros ou então descendentes de brasileiros, um aspecto inédito dentro da história migratória brasileira, pois até então o Brasil era marcadamente um país receptor de imigrantes. Atualmente, os jovens filhos de brasileiros nascidos ou crescidos no Japão tem sido um dos grandes temas de debate, como em questões de educação, de inserção na sociedade japonesa e, depois da crise financeira mundial de 2008, verificou-se uma queda de mais de 120 mil de brasileiros residentes no Japão, correspondendo a 1/3 dessa população, que provavelmente perderam seus empregos e tiveram que retornar ao Brasil nos últimos anos. A (re)adaptação na sociedade de origem para muitos desses brasileiros que passaram anos, se não décadas, tem sido marcada por inúmeras dificuldades. Dentre elas, a questão das diferenças linguísticas e culturais entre o Japão e o Brasil certamente é bastante relevante. Ao mesmo tempo, nesse contexto recente, Morales (2011) tem observado uma revitalização linguística do japonês no Brasil, através da atuação dos retornados brasileiros do Japão como possíveis professores de língua japonesa.

Entretanto, qual a relação entre a migração e a cultura pop japonesa no Brasil? Os entrevistados com origem nipônica - sejam (a) japoneses (nihonjin), sejam (b) descendentes (nikkeijin) - apresentaram em comum um discurso mais pessimista quanto ao futuro da língua japonesa no Brasil, lamentando que isso está se perdendo, uma vez que eles atrelam a língua à manutenção da . No entanto, do grupo (c) de nihongo-jin, ou seja, aqueles sem nenhuma origem japonesa, mas que têm algum tipo de contato com a língua e cultura nipônica, muitos dos quais fãs da cultura pop japonesa contemporânea (embora não só), como anime, mangá e música, dão um tom mais entusiasmado dizendo que a tendência é que a língua japonesa seja cada vez mais difundida. Quem são eles? Por que eles dizem isso?

Para tal, apresentaremos um relato da pesquisa de campo que consistiu em entrevistar pessoas que estavam relacionadas a um desses três universos supramencionados. Neste trabalho, focaremos no grupo (c) de pessoas que não tinham nenhuma origem japonesa, mas que de alguma maneira estavam ligadas à língua ou cultura japonesa (nihongo-jin) e nessa época, em 2011-2012, a maioria tinha algum contato com o mundo da cultura pop japonesa.

\section{Nihongo-jin}

Em agosto de 2011, realizamos entrevistas com alguns representantes de cada um desses três grupos citados no Rio de Janeiro (RJ) e notamos o forte crescimento do 
terceiro grupo, em consequência do grande sucesso da cultura pop japonesa ${ }^{5}$ no Brasil $^{6}$. Dentre eles, entrevistamos Pedro ${ }^{7}$ que promovia eventos de anime na cidade carioca. Ele realizou um mapeamento dos eventos de anime no Brasil e, no final da primeira década do século XXI, reconheceram 50 coordenadores em todo país, contabilizou 196 eventos de anime no Brasil por ano, com um público espectador de 17,5 milhões nesses eventos, que representa, portanto, quase $10 \%$ da população total do Brasil, estimada em mais de 190 milhões, de acordo com o Censo Demográfico de 2010 (IBGE, 2011). Pode-se considerar um dos maiores públicos do mundo, mais do que a China e a Europa, embora a França e a Itália tenham muita força em termos de eventos japoneses, explica Pedro.

O que chamou a nossa atenção foi a informação de que vários eventos acontecem não só em grandes cidades como São Paulo, onde tem a maior comunidade japonesa no Brasil, mas também na região norte-nordeste brasileiro como Ceará e no Maranhão, onde a presença da comunidade japonesa é bem menor. As indagações de como e quando surgiu a popularidade da cultura pop japonesa nessa região, é que nos levou a realizar uma segunda etapa da pesquisa de campo em São Luís, capital maranhense e em Fortaleza, capital cearense, onde fomos entrevistar os organizadores de eventos de anime, assim como os professores de japonês locais, como discorreremos a seguir.

\section{Eventos de anime em São Luís, Maranhão}

De acordo com o entrevistado Pedro, um dos estados brasileiros onde realizavam eventos de anime com maior frequência era Maranhão, no norte do país, onde não tem tanto público, mas tem uma quantidade muito grande de eventos. Por sua vez, tem estados com eventos com muito público, mas não tem muita quantidade de eventos. Por que em Maranhão há tantos eventos? O que eles querem dizer com 'eventos de anime'?

Em agosto de 2012, entrevistamos um grupo de jovens maranhenses que organizam eventos de anime e que foi se estruturando nos últimos anos. Miguel e Robert, jovens de 26 e 27 anos, respectivamente, são desse grupo. Quando eram pequenos, eles assistiam desenhos animados na televisão e os Cavaleiros do Zodíaco (Saint Seiya e a sua abreviação recorrente é CDZ), que começou a ser veiculado em 1994, marcou a vida deles, assim como muitos dessa geração de jovens brasileiros que hoje, na faixa etária de 20 anos, cresceram assistindo esses seriados e, como Miguel e Robert, passaram a organizar eventos.

5. Sobre a cultura pop japonesa, veja por exemplo: RICHIE (2003); GRAVETT (2006); SATO (2007); LUYTEN (2011); MEDEIROS (2011); NAGADO et al. (2011); ALMEIDA (2011); NEVES (2012); OKANO (2012); SOARES (2012).

6. Veja por exemplo: LOURENÇO (2009), SOARES (2009), WINTERSTEIN (2011), SCHUABB (2013).

7. Os entrevistados citados ao longo do texto são mencionados apenas pelo seu primeiro nome. 
"Nossa, eu não troco por nada de hoje com aquele tempo da Manchete. Jaspion, Giraya, Jiban, Winspector... Mas os Cavaleiros do Zodiaco foi o que mais me marcou, eu queria ser o personagem, brincava com os meus irmãos, eu encarnava isso de uma certa forma. Eu desenhava muito também, eu via os desenhos e fazia em quadrinhos. " (Robert, São Luís, 24/08/2012)

Miguel conta que o primeiro a fazer os eventos de cultura pop japonesa em Maranhão foi Breno. Desde 2001, organizou um evento que se chamava SAF (São Luís Anime Festival), que Miguel considera "bem tradicional", na medida que foi capaz de dar continuidade ao longo dos últimos dez anos. Breno sofreu um acidente que o deixou paraplégico, dificultando a locomoção. E o que o "trouxe à vida" foi o fato de estar nesse meio, do anime e também do mangá, que lia muito. A sua mãe relata o seguinte, sobre o envolvimento de Breno com a cultura japonesa:

"O ponto importante nesse trabalho que vem se desenvolvendo é exatamente a evolução desse gosto pela cultura japonesa voltada para essa área do anime e do mangá. Isso é muito salutar, então as famílias também apoiam, nós apoiamos, nós fazemos parte do grupo dele. No caso especifico dele, ele nasceu perfeito, sem nenhum problema, depois teve um probleminha de saúde e o amor pela cultura japonesa, pelo anime o fez... ele era canhoto e então perdeu o movimento do lado esquerdo e pelo gosto, por gostar muito, por estudar japonês, ele estuda, fala um pouco já e tal, então, precisava escrever. Para escrever ele teve que se esforçar com a mão direita. E na verdade, eu tenho assim que confessar que eu não valorizava muito essa história, né? Nós fomos a São Paulo fazer uma revisão médica, fomos lá passear e vamos aproveitar e fazer uma revisão. E nessa revisão o médico viu que a evolução dele estava muito boa e perguntou se ele estava estudando. Bom, ele começou, mas aí deu uma parada e não quis mais. Mas ele está lá fazendo japonês. Japonês? Pronto, está explicado. Então, todas as conexões voltando, ele associou toda a evolução do tratamento dele exatamente porque ele tinha voltado a se empenhar a estudar, empenhado para poder escrever com a mão direita e com isso o cérebro foi se reorganizando, os movimentos deles também foram e ai a gente passou a valorizar bastante, porque viu que era uma coisa que ele gostava, que era salutar para a vida dele, que o deixava feliz e qual é a mãe que não quer ver o seu filho feliz? Então a gente passou a apoiar." (Solange, São Luís, 24/08/2012)

\section{Sobre o primeiro evento de anime, Breno conta:}

"Eu realizei o primeiro evento de anime aqui baseado em matérias que eu via em revistas informativas, inclusive o que chamava Animax que tinha, e tinha muitas matérias de eventos em Curitiba, São Paulo. Até hoje me lembro de uma matéria sobre Animencontro dando 600 pessoas. Hoje em dia, com certeza, um encontro desses já dá milhares e milhares de pessoas, mas naquela época para mim parecia tão inatingível. Isso foi, sei lá, em 1995, 96. Porque Animax terminou no número 50, perto da época do começo do Pokemon. Então, por ai tira, né? Muito tempo... lembro-me ter visto fotos de cosplayers e quando quis fazer a primeira vez, o pessoal achou que eu estava meio pirado, mas depois surrealmente virou um hobby assim que o pessoal podia começar a gostar.” (Breno, São Luís, 24/08/2012) 
Desde 2010, Breno se juntou com um amigo e reuniram os seus eventos - o 'Bakuhatsu' (que é o nome de um estande de venda de acessórios, de bonequinhos, camisas, bottons, colares do seu amigo) e o seu próprio evento, o SAF (São Luís Anime Festival), e que passou a se chamar 'Bakusaf'. O próprio Breno, com o incentivo da família, montou uma loja no fundo da sua casa, como empreendedor, com registro jurídico, com venda virtual por site, também tem montando estande em eventos de animes da região, faz a divulgação de seus produtos (como gachapons, chaveiros, camisetas, straps, pelúcias, toucas, mouse pad, relógios de pulso personalizados etc.) e organiza e divulga seus eventos através da internet e redes sociais virtuais - antes no Orkut e agora no Facebook. Além disso, criou uma mascote chamada 'Momo-chan' (um desenho de uma menina de vestida de colegial, de cabelo roxo, com orelhas e rabo de uma gata), que era o perfil utilizado no Facebook para divulgar a sua loja e seus eventos, pois assim é a forma mais fácil de atrair gente para o estande, diz o próprio Breno, além de panfletagem pela cidade toda que ele fazia pessoalmente. Breno acredita à evolução da tecnologia de informação o sucesso dos eventos:

\begin{abstract}
"E sem falar que as redes sociais ainda estavam engatinhando nessa época, né? Então hoje em dia é tudo muito mais fácil. Eu vi pela evolução, na época do Orkut a divulgação era uma coisa. Quer dizer, antes do Orkut era uma coisa. Depois do Orkut ficou bom, para fazer a divulgação ajudou muito. E quando passou a ter os grupos no Facebook, passou a ajudar muito mais porque no Facebook você divulga para uma pessoa e essa pessoa já divulga para outras. Então, quer dizer, vira uma progressão geométrica. Foi só aumentando. Hoje você pode fazer 10, 15 mil convites, dessas 15 mil, se 2, 3 mil forem, você já lota o seu evento, certamente." (Breno, São Luís, 24/08/2012)
\end{abstract}

Por conta desse envolvimento com a cultura pop japonesa, Breno estuda japonês no Instituto Cultural Nipo-Brasileiro de Maranhão, um dos únicos lugares que ensina a língua japonesa na cidade, onde o seu professor, Sr. Yamada, tem uns 10 alunos frequentando. Segundo ele, antigamente havia umas 100 famílias nikkeis, sendo que muitos vieram do sudeste do Brasil - São Paulo, Paraná ou Minas Gerais - isto é, não foi uma migração direta do Japão para essa região. Sr. Yamada veio do Japão ainda jovem nos meados da década de 1970 ao Brasil. No início havia projetos de desenvolvimento da Amazônia da JICA (Agência de Cooperação Internacional do Japão) e ele sonhava com isso, por isso veio para o Brasil por conta própria. Ele se formou numa escola técnica agrícola no Japão, além de praticar e ensinar artes marciais e, com espírito aventureiro, já morou em várias cidades no Brasil (São Paulo, Goiás, Pará etc.), até chegar em São Luís. Ele conta que no começou o objetivo do Instituto era ensinar língua japonesa aos nikkeis da colônia que não dominavam o idioma corretamente. De repente, a economia japonesa foi melhorando e foi aumentando o número de bolsistas intercambistas ao Japão e eles se tornaram o público alvo. Mais recentemente, nos últimos dez anos, a 
maioria dos alunos tem procurado o curso de japonês por influência do mangá. A partir desse contato inicial, os amantes de mangá passaram a querer aprender japonês, a gostar da cultura japonesa, alguns mostraram desejo de ao Japão.

Ainda de acordo com o Sr. Yamada, embora muitos jovens estejam interessados na cultura pop japonesa e pareçam numerosos, na verdade eles ainda são uma minoria em relação à população total da cidade. Isso corrobora com a ideia que se tem sobre a cultura pop japonesa no Japão, enquanto uma subcultura, ou seja, é parte de uma cultura maior.

Outra coisa que chamou atenção é a presença cada vez maior de K-pop, isto é, música e dança pop coreana contemporânea nos eventos de cultura pop japonesa, onde até então era focada no J-pop (música e dança pop japonesa). É o que relatam os jovens ludovicenses:

Aldo: Grupo de K-pop está aparecendo direto.

Robert: Eu falei do K-pop das sul-coreanas. É oriental, mas seria indiretamente japonês, né? É algo que está entrando agora, o que rola.

Breno: É, está entrando, mas os fãs de anime, principalmente os daqui, eles absorvem não só a cultura japonesa, mas quase tudo da cultura oriental. Ou seja, pode ser tailandês, pode ser coreano, japonês, chinês - se for bom, o pessoal está consumindo.

Robert: as culturas a fins que estão próximas. É atrativo.

Breno: É atrativo, por quê, o pessoal vê, é oriental, é bom.

(São Luís, 24/08/2012).

Talvez o fato de um não descendente organizar um evento, a princípio, de cultura japonesa e expandir para a cultura oriental, englobando outras culturas asiáticas, não seja um problema, ao contrário, é expansão. Já, se fosse alguém de origem japonesa (nihonjin ou nikkeijin) organizasse esses eventos, talvez se sentisse comprometido em difundir basicamente a sua cultura de origem e desse modo, englobar outras culturas, como a coreana e a chinesa, poderia ser algo mais incômodo, diante das rivalidades étnicas e históricas. Jovens sem nenhuma origem japonesa, mas com envolvimento com um aspecto dessa cultura, não teriam exatamente esse comprometimento, porque está partindo de um outro ponto de vista, de um outro ângulo.

Muitos dos jovens maranhenses que gostavam de desenhos animados japoneses fizeram disso tema de suas monografias acadêmicas. O próprio Miguel que fez administração e marketing, utilizou o seu projeto de metodologia que desenvolveu na faculdade e aplicou na empresa de produção cultural para a 
organização de evento chamado Matsuri ${ }^{8}$, um dos maiores eventos de cultura pop japonesa de São Luís, que atrai um público de dois mil visitantes em um final de semana.

Esses eventos que antes aconteciam semanalmente, evoluíram ao longo dos últimos dez anos, não só ganhando experiência cada vez que realizava, mas também pela época em que a popularização e/ou maior acesso à internet facilitou os contatos e a divulgação dos encontros. Se no final dos anos 1990 e início dos anos 2000 os primeiros eventos consistiam em reuniões de amigos que faziam sessões de exibição de animes e concursos de desenhos ${ }^{9}$, os recentes passaram a ter uma variedade de atrativos, para contemplar diferentes públicos num evento que, como eles mesmos dizem, é para todas as idades. O próprio Miguel relata que o público está ficando cada vez mais jovem e, ao mesmo tempo, os familiares que acompanham esses jovens também comparecem e se entretêm com diversas atividades oferecidas no evento.

Alguns meses depois da pesquisa de campo, realizou-se o Matsuri V, em novembro de 2012, um dos maiores eventos de anime de São Luís. Além da exibição de anime, havia várias salas temáticas de tokusatsu, yaoi, J-rock, K-pop; workshops de maquiagem para cosplay, lolitas; nas edições anteriores já teve de ikebana, shiatsu; demonstração de artes marciais como kendô, shows com cantores de anime song, de bandas locais de $J$-rock, convidados especiais como cosplayers profissionais, dubladores; concurso de $\operatorname{cosplay}{ }^{10}$, de lolitas ${ }^{11}$, animekê (karaokê de anime song), arena de games, campeonato de cards, além de estandes de venda de produtos e outras atrações, realizadas em espaços cada vez maiores. Nesse sentido, pode-se dizer que as organizações de eventos foram se profissionalizando ao longo dos anos, procurando oferecer uma melhor infraestrutura - como ar condicionado, banheiros, estacionamento, cantina, maior espaço de circulação, segurança etc..

8. Matsuri produções: https://www.facebook.com/matsuri.producoes?fref $=$ ts (acessado dia 14/07/2015).

9. Um dos entrevistados gostava muito de desenhar mangá e a partir disso fez uma monografia sobre a utilização do mangá em sala de aula", na Graduação em Licenciatura em Letras, com habilitação em Língua Portuguesa (LEITE JR., 2011).

10. Nesse ano de 2012, São Luís passou a fazer parte do circuito nacional de concurso de cosplay do World Cosplay Summit (WCS), conforme http://henshin.uol.com.br/wcs/ (acessado dia 14/07/2013).

11. Uma das entrevistadas fez uma monografia sobre a moda lolita na área de Comunicação Social (MENDES, 2012). Veja também BERNARDES (2011) sobre a construção de sociabilidade virtual e visual das gothic lolitas. Uma das convidadas especiais foi a lolita Akemi Matsuda, uma das mais conhecidas no Brasil atualmente. 
Ao entrevistar posteriormente o cantor de anime song, em fevereiro de 2012, no Rio de Janeiro, Rodrigo ${ }^{12}$ relata que hoje em dia há eventos de anime em todo o Brasil e há diferenças regionais. E o nordeste é um dos lugares que ele mais gosta de se apresentar, pois exatamente por ser uma região mais carente de acesso à cultura pop japonesa, diferente da região Sul-Sudeste, o público é mais empolgado e passa uma energia impressionante durante os seus shows.

\section{SANA, em Fortaleza (CE)}

Essas diferenças regionais ficaram claras ao irmos à outra cidade, Fortaleza, no Ceará. Lá entrevistamos Igor que é um dos organizadores do SANA - Super Amostra Nacional de Animê ${ }^{13}$ - que hoje é considerado o segundo maior evento de anime do Brasil, ficando atrás apenas do evento realizado em São Paulo. Começou a realizar os eventos desde 2000 e na sua última edição, em 2011, agregou um público de 60 mil visitantes em um final de semana.

Com outro background e capital social, econômico, social e político, o perfil dos organizadores de Fortaleza difere bastante dos de São Luís. Igor tem 23 anos, é economista e tem uma firma de investimentos, trabalha com bancos e também com alguns setores empresariais e para tal tem uma equipe própria. Entre os seus amigos que compõem a diretoria da organização do evento, um é engenheiro civil que trabalha com obras na prefeitura; outro é administrador e trabalha com eventos; o outro é contador e tem uma gráfica; e o último é administrador e dono de restaurante.

Mas a trajetória inicial é bastante parecida com a de diferentes organizadores de eventos de cultura pop japonesa - quando pequenos, nos anos 1990, assistiam desenhos na televisão. No caso de Igor também os Cavaleiros do Zodíaco influenciaram muito a sua infância e mais tarde isso virou um grande empreendimento para ele e seus amigos. Segundo ele, até o final dos anos 1990, os fãs de animes gravavam os episódios das suas séries favoritas que passavam na televisão. Quando parou de passar esses desenhos na televisão, eles trocavam vídeos cassetes VHS em encontros semanais numa praça, como aconteceu em Fortaleza, como Igor relata:

"Quando parou, a Rede Manchete fechou e nenhuma emissora passou nada. Mas muita gente tinha gravado nas fitas VHS vários episódios. O pessoal tinha fita completa em casa, antigamente. A gente via nas revistas, porque tinha algumas revistas aqui no Brasil que falavam um pouco sobre as séries japonesas, o que estava passando lá... não tinha internet,

12. Rodrigo, que também assistia aos desenhos animados na televisão como Os Cavaleiros do Zodíaco e Dragon Ball quando pequeno e se tornou um cantor de anime song. Atualmente faz a versão brasileira da trilha sonora de abertura desses desenhos mencionados. Veja o seu site: http://rodrigo-rossi. $\mathrm{com} /$ (acessado dia 14/07/2015).

13. Ver https://www.facebook.com/SanaSuperAmostraNacionalDeAnimes (acessado dia 14/07/2015). 
né? As pessoas começaram a se encontrarem na Praça Portugal e era assim, um amigo que trazia um outro amigo, e esse amigo trazia mais dois, três amigos, e aí começou a lotar. E o que o pessoal fazia lá? Eles trocavam fitas. Você tinha uma fita de um seriado ou de um desenho, e a outra pessoa também, ai você trocava e debatiam sobre essas séries. Quando foi em 2000, a gente teve uma ideia, 'Ah, vamos criar um evento, vamos juntos, chamar pessoas que também tem interesse na cultura japonesa pop...'” (Igor, Fortaleza, 27/08/2012)

Ele não imaginava que o seu evento de anime ganhasse tamanha proporção. No caso do Sana ${ }^{14}$, Igor conta que conseguiu apoio do setor público da cidade, como a câmara municipal de Fortaleza, do governo do estado do Ceará, do Banco do Nordeste, da televisão, rádio e jornal regional, com cobertura midiática regional bastante articulada, além das lojas de games e cursos de programação visual:

"O que a gente diz que hoje o público otakuls já vai para o evento. A gente tem que atrair cada vez mais, porque o nosso objetivo é difundir essa cultura, são as pessoas que são os curiosos. Então a gente está fazendo o quê? Colocando outdoors nas ruas, colocando placas atrás de ônibus e fazendo o máximo de divulgação possivel porque a parte de mídia - internet, rádio e TV-já é tranquilo com essa parceria. O que a gente diz, muita gente pergunta: por que o Sana se destacou tanto no Ceará? Será que tem diferença? Eu digo, eu acho que não é uma especificidade daqui. Acho que foi a seriedade com que a gente tratou o projeto. Eu acho que se tivesse sido em alguns outros estados, talvez, Goiás, Brasília, Mato Grosso, Pernambuco também, Bahia, teria acontecido se as pessoas lá tivessem... também digo que tivemos várias oportunidades. Tivemos o apoio do sistema da Globo daqui, tivemos incentivo público, tivemos a capacidade de transformar, uma fundação que abriu as portas juridicamente para isso, eu vejo que ainda não tem muito isso." (Igor, Fortaleza, 27/08/2012).

\section{Para viabilizar o evento, criou a Fundação Cultural Nipônica Brasileira (FCNB):}

"Porque essa Fundação (FCNB) torna o objetivo do projeto legal e conceituado. Eu tenho toda estrutura, instrumentos jurídicos para conseguir patrocinios, para fechar contratos, todos os contratos são feitos pela fundação, os próprios aluguéis do local do evento são todos feitos pela fundação, porque ele pede certidões negativas de débito, você não está

14. Assim como em São Luís, em Fortaleza encontramos algumas monografias acadêmicas cujo tema aborda sobre cultura pop japonesa, especialmente sobre o Sana, como BARATA (2009) e SOBREIRA (2011), ambas na área de Comunicação Social, com habilitação em Publicidade e Propaganda, mas em universidades diferentes.

15. "Otaku" é um termo utilizado para se referir aos aficionados de anime e mangá. No Japão tem uma conotação mais pejorativa, referindo-se aos jovens rapazes com dificuldade de se sociabilizar e que se isola em seu quarto cercado pelo mundo do mangá e anime. Já no Brasil, otaku refere-se aos fãs da cultura pop japonesa, mas sem tanta alusão ao isolamento social, chamado também de hikikomori que SAITO (2012) aborda. Sobre os diferentes usos do termo 'otaku' no Japão e no Brasil, veja: LOURENÇO (2009); SOARES (2009) E WINTERSTEIN (2011) 
devendo nada, então você torna o projeto não de uma pessoa ou de outra, mas um projeto de um grupo de pessoas. Então isso dá uma validade jurídica, dá uma credibilidade maior para quem está fazendo isso. Eu vejo isso como um ponto crucial.” (Igor, Fortaleza, 27/08/2012).

Um dos destaques de seu evento é a ênfase no videogame. Ele conta com as grandes marcas internacionais como a Microsoft, Sony e Nintendo para premiar os concursos de games. Além disso, ele traz atrações internacionais como cantores japoneses dos seriados, dubladores, faz apresentações de filmes, séries e animações, artes-marciais, campeonatos de cosplay, música, tenda-eletrônica, palestras, workshops e também monta estandes de vendas.

Além disso, nesses grandes eventos de anime, também se organizam "caravanas" que são grupos de várias cidades da região que se organizam para ir de ônibus fretado e participar de eventos como o Sana. Os entrevistados de São Luís também se organizam, providenciando o transporte e a hospedagem, para irem até Fortaleza para participar do Sana como público. Podemos dizer que isso faz parte da profissionalização dos serviços relacionados aos eventos de cultura pop japonesa.

Através desse evento, Igor diz que procura divulgar a cultura japonesa. Embora a ênfase seja na cultura moderna, ele procura mostrar a cultura tradicional japonesa, sendo que a maior característica é a culinária e as artes marciais como esporte. Para ele, esses aspectos da cultura japonesa influenciam e ajudam a vida das pessoas aqui no Brasil e que pode ser utilizada como instrumento de transformação nessa área de profissionalização e também de abertura de oportunidades.

Ele mencionou o exemplo de uma moça que começou com o projeto de moda japonesa no evento em Fortaleza. Ela fez todas as roupas no estilo japonês, contou com amigas modelos e fez o desfile. A ideia dela deu certo, começou a fazer roupas, a vender e ela mesma desfilava. Hoje ela está desfilando na Tailândia, na Cingapura, na China e já foi para o Japão. Então, começou um pequeno movimento no evento. Assim, existem oportunidades nesses elementos da cultura japonesa para adaptar para uma realidade brasileira e transformar aquilo ou num entretenimento ou ofício real para a pessoa. Isso acontece com a escola de artes virtuais, com essa parte de moda, de música. Tratam-se, por exemplo, de cursos que começam a surgir de pessoas para querem saber como tocar um instrumento, pois querem tocar as músicas dos desenhos. Há, enfim, como apropriar de aspectos importantes da cultura moderna e da cultura tradicional japonesa, trazer para a realidade brasileira e provocar um impacto na vida das pessoas.

Em Fortaleza, entrevistamos também a Profa. Iwakami que leciona língua japonesa na Universidade Estadual do Ceará (UECE). Ela é descendente de japoneses que nasceu e cresceu em São Paulo e no início dos anos 1980 passou no concurso público na área de Letras e lecionou português durante 7 anos no interior do estado. No início dos anos 1990 foi transferida para Fortaleza onde implementou o curso de 
extensão de língua japonesa na $\mathrm{UECE}^{16}$. Durante a entrevista, ela relatou o perfil dos estudantes que inicialmente possuíam interesse pela cultura tradicional japonesa, mas que a partir de 2000, o perfil foi mudando para um público mais jovem, com interesse em cultura japonesa mais contemporânea. A maioria dos frequentadores do curso de japonês não são descendentes nipônicos, embora houvesse alguns. Nessa região no nordeste brasileiro, há poucos moradores de origem japonesa, mas ainda assim existe $\mathrm{o}$ Instituto Cultural Nipo-Brasileiro do Ceará, que conta com cerca de 200 famílias nikkeis associadas, sendo que muitas delas vieram de São Paulo e Paraná, assim como foi em São Luís. Dentre esses alunos mais jovens, o motivo principal para cursar japonês é o interesse por anime e mangá e chega a mencionar o Sana como o grande evento de anime da cidade e da região nordeste. Assim como no Rio de Janeiro e em praticamente todo o Brasil, a cultura pop japonesa tem sido uma importante porta de entrada de jovens para se interessarem por língua e cultura nipônica, como UEDA e MORALES (2006) também constataram.

Junto com a Profa. Iwakami, entrevistamos Abimael, um aluno seu que acabara de retornar do Japão, após uma estadia para cursar língua japonesa, ao ser contemplado com uma bolsa de estudos da Fundação Japão, um órgão do governo japonês. Abimael que tinha 28 anos, também faz coro com os outros jovens entrevistados:

\begin{abstract}
"A questão do Saint Seiya (Cavaleiros do Zodíaco) foi que surgiu em 1994 e todo mundo começou a assistir, todos da minha idade, todos os meninos. Então, era uma febre, digamos assim. Todo mundo assistia e no dia seguinte comentava na escola, então acho que o interesse surgiu daí. Talvez porque é um anime voltado para meninos, shônen, então acabou atraindo e era novidade, então foi realmente uma coisa que atraiu. A partir dai vieram outros animes na mesma temática e ai foi aumentando o interesse do brasileiro pelo anime, a partir daí, acho que o Saint Seiya foi o primeiro que deu pontapé inicial. Antes de Saint Seiya, não sei bem como fala em japonês, tokusatsu? São aqueles Jaspion, Changeman, Flashman, Giraya, antes do Saint Seiya eram esses que faziam sucesso entre os brasileiros, no final da década de 1980, inicio de 1990. E a partir daí, em 1994 surgiu o Saint Seiya e o anime começou a se tornar popular, era novidade, era diferente de todos os desenhos que estávamos acostumados a ver naquela época. Foi uma coisa que tinha diferencial." (Abimael, Fortaleza, 26/08/2012)
\end{abstract}

Em MONTE (2010:14-15), temos a confirmação de que diversos desenhos animados japoneses vieram ao Brasil nas décadas de 1970 e 80 . A TV - especialmente aberta - foi e continua sendo peça fundamental para o sucesso dos animes em todo o país, mesmo com VHS dos anos 80/90, DVD dos anos 2000, a internet e agora o Blu-Ray.

16. Sobre a sua experiência de ensino de língua japonesa no nordeste, veja IWAKAMI (2012). 


\section{Considerações finais}

As entrevistas realizadas em São Luís (MA) e Fortaleza (CE) nos revelaram que, embora o perfil dos organizadores de eventos de anime dessas cidades seja distinto, notamos que tem em comum o ponto de partida: os desenhos animados japoneses veiculados na televisão aberta nos meados dos anos 1990 e que marcou toda essa geração de jovens. Também tem em comum o fato de terem sido consumidores e públicos de eventos num primeiro momento e depois passaram a dedicar o seu tempo e trabalho na sua organização. Os recursos dos quais dispunham diferem, com realidades regionais, sociais, econômicos, políticos diversos, no entanto, são jovens que correm atrás de seus sonhos: trabalhar com aquilo que lhes motivam e assim compartilhar isso com as gerações seguintes e com um público mais abrangente. Um hobby que virou business. Mas, mesmo que todos eles se dediquem à organização de eventos, têm outras ocupações e fontes de rendas.

O boom de cultura pop japonesa no Brasil e em outros países, a partir do início do terceiro milênio, somado ao desenvolvimento tecnológico na comunicação por meio do acesso à internet, trouxe não só novas formas de sociabilidades, mas também novos desafios para o ensino de língua e cultura japonesa, uma vez que o perfil dos alunos que procuram essas disciplinas foi mudando. Como lidar com essa nova realidade?

Por um lado, observamos que o mundo pop contemporâneo tem sido a porta de entrada para muitos que se interessam pelos outros aspectos da cultura japonesa. Por outro lado, isso nos faz repensar sobre a relação entre a migração e a cultura pop japonesa no Brasil, isto é, a forma de se relacionar, objetivamente e subjetivamente, com o mesmo Japão, que é diferente, sob perspectivas, critérios e registros distintos. É verdade que os brasileiros descendentes de japoneses (nikkeijin) também tiveram contato com os mangás e animes ao longo de suas vidas, mas o fato de ter origem étnica e cultural japonesa, a sua relação consanguínea, biológica, psicológica, emocional e simbólica com a terra de seus ancestrais, fez com que mergulhasse num contexto que de alguma maneira era focado na comunidade japonesa. E a sua relação com a sociedade brasileira, por bem ou por mal, tendo no horizonte a manutenção da identidade japonesa idealizada pelas primeiras gerações, com a preocupação de perpetuar o legado nipônico, inevitavelmente trouxe muitos conflitos em várias dimensões. Mas o próprio Japão mudou e a massificação da cultura pop japonesa não deixa de indicar tais transformações. E essas mudanças, dentre outras, indicam que a(s) japonesidade(s) - termo criado por Machado (2011) - no Brasil não se limita mais tão somente à comunidade japonesa no Brasil, que até então se acreditava ser o representante legítimo da cultura japonesa no país. Como Machado (apud) discute, há múltiplas possibilidades de se abordar a(s) japonesidade(s) - no plural - no Brasil. A difusão massificada da cultura pop japonesa no Brasil tem ocorrido através de outros canais como a televisão, vídeos e internet, isto é, mídia ou comunicação em massa, junto com o consumo de animes, mangás, música assim como os inúmeros produtos comercializados (SEVERIANO, ESTRAMIANA, 2006) 
que veio a influenciar toda uma geração de jovens brasileiros, não necessariamente pela mediação da comunidade japonesa no Brasil, embora haja, claro, áreas de intersecção e de sobreposição. Se a empolgação deles desafia os paradigmas nos quais pautávamos até então, como por exemplo, como ensinar ou abordar a língua e cultura japonesa, ela nos convida a rever os nossos olhares e a abrir um leque de possibilidades que podem nos surpreender. Temos muito a aprender com eles.

\section{Referências Bibliográficas}

ALMEIDA, Roberta Regalcce de. Samurai Champloo: O tradicional remixado de Shinichiro Watanabe. In GREINER, Christine e SOUZA, Marco (Orgs.) - Imagens do Japão: pesquisas, intervenções poéticas, provocações. São Paulo: Ed. Annablume / Fundação Japão, 2011, p.13-26.

BARATA, Camila Santos Dumont. Estudo de Caso do SANA: A introdução da cultura pop japonesa em Fortaleza. Monografia de graduação em Comunicação Social, Habilitação em Publicidade e Propaganda, Faculdade 7 de Setembro (FA7), Fortaleza, CE, 2009.

BERNARDES, Thales Augusto. Gothic Lolitas: A construção de sociabilidade por meio do 'Virtual' e 'Visual'. Revista Habitus - Revista eletrônica dos alunos de graduação em Ciências Sociais - IFCS, UFRJ, v. 9, n. 2, 2011, p.110-121. Disponível online (acessado dia 22/02/2012): http://www.habitus.ifcs.ufrj.br/ojs/ index.php/revistahabitus/article/view/130/156

CARNEIRO, Maria Luiza Tucci; TAKEUCHI, Márcia Yumi (Orgs.). Imigrantes Japoneses no Brasil - Trajetória, imaginário e memória. São Paulo: Editora da Universidade de São Paulo, 2010.

GRAVETT, Paul. Mangá - Como o Japão reinventou os quadrinhos. São Paulo: Conrad Editora do Brasil, 2006.

HOBSBAWM, Eric. Introdução. In: HOBSBAWM, Eric. RANGER, Terence. A Invenção das Tradições. Rio de Janeiro: Paz e Terra, 1984, p.9-23.

IBGE (Instituto Brasileiro de Geografia e Estatística). Censo Demográfico de 2010. 2011. http://www.ibge.gov.br/home/estatistica/populacao/censo2010/default.shtm (acessado dia 11/07/2013).

IWAKAMI, Laura Tey. Uma Experiência de Ensino da Língua Japonesa no Nordeste: O curso de Japonês no Núcleo de Línguas Estrangeiras da Universidade Estadual do Ceará. In: MUKAI et al. (Orgs.) - A Língua Japonesa no Brasil - Reflexões e experiências de ensino e aprendizagem. Campinas: Pontes Editores, 2012, p.5577. 
LEITE JÚNIOR, Aldo Ferreira. A Utilização do Mangá em Sala de Aula. Monografia de Graduação em Licenciatura em Letras, com habilitação em Língua Portuguesa, da Faculdade Atenas Maranhense. São Luís, MA, 2011.

LOURENÇO, André Luiz Correia. Otakus: Construção e representação de si entre aficionados por cultura pop nipônica. Tese de Doutorado em Antropologia Social, Museu Nacional, Universidade Federal do Rio de Janeiro (UFRJ), 2009. Disponível online (acessado dia 30/03/2012): http:/teses2.ufrj.br/Teses/ PPGAS_D/AndreLuizCorreiaLourenco.pdf

LUYTEN, Sônia. Mangá: O poder dos quadrinhos japoneses, São Paulo: Hedra, 2001.

MACHADO, Igor J. R. (Org.). Japonesidades Multiplicadas - Novos estudos sobre a presença japonesa no Brasil, São Carlos (SP): EdUFSCar, 2011.

MEDEIROS, Aluizio. Mangá, Animê, Cosplay e J-rock: Cultura pop japonesa do litoral ao sertão. In: MOTTA, Antonio (org.) - O Japão não é longe daqui. Recife: Ed. UFPE e Toquio: Japan Foundation, 2011, p.117-135.

MENDES, Mariza Rosa. A Cultura da Elegância: Uma análise da comunicação entre adeptas da moda lolita na rede social Poupée Girl. Monografia de Graduação em Comunicação Social da Universidade Federal do Maranhão, Bacharel em Comunicação, habilitação em Rádio e TV. São Luís, MA, 2012.

MONTE, Sandra. A Presença do Anime na TV Brasileira. São Paulo: Editora Laços, 2010.

MORALES, Leiko Matsubara. Cem Anos de Imigração Japonesa no Brasil: O japonês como língua estrangeira. Tese de Doutorado em Linguística, Faculdade de Filosofia, Letras e Ciências Humanas, Universidade de São Paulo (USP), 2008.

MORALES, Leiko Matsubara. Revitalização Linguística do Japonês no Brasil: A atuação dos retornados brasileiros do Japão como professores de língua japonesa. Travessia, v. 69, São Paulo, 2011, p.31-46.

MORIWAKI, Reishi; NAKATA, Michiyo. História do Ensino da Língua Japonesa no Brasil. Campinas: Editora Unicamp, 2008.

MOTOYAMA, Shozo. Sob o Signo do Sol Levante - Uma história da imigração japonesa no Brasil, vol. I (1908-1941). São Paulo: Paulo’s Comunicação e Artes Gráficas, 2011.

MUKAI, Yûki; JOKO, Alice Tamie; PEREIRA, Fausto Pinheiro (Orgs.). A Língua Japonesa no Brasil - Reflexões e experiências de ensino e aprendizagem. Campinas: Pontes Editores, 2012. 
NAGADO, Alexandre; MATSUDA, Michel; e GOES, Rodrigo de. Cultura Pop Japonesa - Histórias e curiosidades, 2011. Disponível online (acessado dia 22/02/2012): http://nagado.blogspot.com.br/2011/12/cultura-pop-japonesa-ebook-gratuito.html

NEVES, Mauro. As Origens do J-pop e a sua Diversificação: Algumas reflexões. In: GREINER e SOUZA (Orgs.) - Imagens do Japão - Experiências e invenções. São Paulo: Annablume, Fundação Japão, 2012, p.85-100.

NOMOTO Kyoko 野本京子 (Editor).『2011-2013年度 科学研究費補助金（基 盤研究(B)）研究成果報告書〈紐帯としての日本語〉日本人社会、日系コ ミュニティ、「日本語人」の生活言語誌研究』-2011-2013 Research Result of Scientific Research Fund on "Japanese Language as a Bond in the Oversea: A Study for Linguistic Life of Japanese Community, Japanese Descent Community, 'Nihongo-jin' Community. 課題番号 (Edition number): 23310176 ，東京外 国語大学大学院総合国際研究院 - International Center for Japanese Studies, Tokyo University of Foreign Studies, 2014, 68pp.

OKANO, Michiko. A Imagem do Japão Contemporâneo. In: GREINER e SOUZA (Orgs.), Imagens do Japão - Experiências e invenções. São Paulo: Annablume, Fundação Japão, 2012, p.127-147.

RICHIE, Donald. The Image Factory: Fads \& fashions in Japan. London: Reaktion Books, 2003.

SAITO, Cecília Noriko Ito, 2012. Hikikomori e Clausura no Japão. In: GREINER e SOUZA (Orgs.) - Imagens do Japão - Experiências e invenções. São Paulo: Annablume, Fundação Japão, 2012, p.101-124.

SAITO, Hiroshi (Org.). A Presença Japonesa no Brasil. São Paulo: T. A. Queiroz / Edusp, 1980.

SAKURAI, Célia. Imigração Tutelada: Os japoneses no Brasil. Tese de Doutorado em Ciências Sociais, Instituto de Filosofia e Ciências Humanas (IFCH), Universidade Estadual de Campinas (UNICAMP), 2000.

SAKURAI, Célia; COELHO, Magda Prates (Orgs.). Resistência \& Integração: 100 anos de imigração japonesa no Brasil. Rio de Janeiro: Instituto Brasileiro de Geografia e Estatística (IBGE), 2008.

SASAKI, Elisa Massae. Ser ou Não Ser Japonês? A construção da identidade dos brasileiros descendentes de japoneses no contexto das migrações internacionais do Japão contemporâneo. Tese de Doutorado em Ciências Sociais, IFCH, UNICAMP, 2009. Disponível online na Biblioteca Digital da Unicamp: http:// 
www.bibliotecadigital.unicamp.br/document/?code $=000442741$

SATO, Cristine A.. Japop - O poder da cultura pop japonesa. São Paulo: NSP-Hakkosha, 2007.

SCHUABB, Rafael. Articulação e Codificação de Sentidos no Estrato Imagético de Histórias em Quadrinhos Japonesas. Dissertação de Mestrado em Linguística, Instituto de Letras, Universidade do Estado do Rio de Janeiro, 2013.

SEVERIANO, Marina de Fátima Vieira e ESTRAMIANA, José Luís Álvaro. Consumo, Narcisismo e Identidades Contemporâneas - Uma análise psicossocial. Rio de Janeiro: Ed. Uerj, 2006.

SOARES, Bruno da Silva. Os Eventos de Anime e a Difusão da Cultura Japonesa. Monografia de Graduação em Letras, Bacharel em Letras, Português-Japonês, Universidade do Estado do Rio de Janeiro. Rio de Janeiro, RJ, 2009.

SOARES, Gabriel Theodoro. Cosplay: Quando a realidade virou fantasia e a fantasia virou realidade. In: GREINER e SOUZA (Orgs.) - Imagens do Japão - Experiências e invenções. São Paulo: Annablume, Fundação Japão, 2012, p.197-211.

SOBREIRA, Fernanda Chagas. Japão no Brasil - Fãs, identificação e consumo no SANA Feste 2011 e na Rádio AniMix. Monografia de Graduação em Comunicação Social da Universidade Federal do Ceará, Bacharel em Comunicação Social, habilitação em Publicidade e Propaganda. Fortaleza, CE, 2011.

TAKEDA, Chika; KITAHARA, Satomi. 武田千香、キタハラ・タカノ・サトミ 「ブラジル日系人・日本人・日本語人に関する調査」- "Research about nikkeijin, nihonjin and nihongo-jin in Brazil". In: NOMOTO Kyoko, Op. Cit., 2014, p.6-14.

UEDA, Nancy Naomi; MORALES, Leiko Matsubara. A Presença da Mídia na Socialização Contemporânea dos Jovens: O caso dos anime como convite ao estudo da língua japonesa. Estudos Japoneses, nº 26, 2006, p.77-96, São Paulo: FFLCH / USP.

WINTERSTEIN, Cláudia, 2011. Otakus e Cosplayers - J-pop e japonesidades. In: MACHADO, Igor (Org.). Japonesidades Multiplicadas - Novos estudos sobre a presença japonesa no Brasil, São Carlos (SP): EdUFSCar, 2011, p.143-159. 